for materials research..

Chemistry Simulation Software: Reaction Design's CHEMKIN 3.5 software incorporates graphical post-processing and dynamic memory management without requiring an external Fortran compiler. An application user interface features a point-and-click system that guides users through pre-processing and post-processing steps and verifies that input files are processed correctly. A graphical postprocessor automatically extracts $X-Y$ pairs from solution files and provides visual analysis. Data also can be imported to and exported from external programs.

Circle No. 60 on Inside Back Cover.

Polarizing Microscopes: Nikon's Eclipse E600POL and E400POL offer high numerical apertures and long working distances, and can be upgraded for advanced techniques. Both models rely on the $\mathrm{CFI}_{60}$ infinity optical system. Diascopic and episcopic polarizing observation is possible, and the illuminator sharply captures images of low-reflectance opaque specimens. Free brochure includes photos, statistics, and images of specimens as viewed at different magnifications.

Circle No. 61 on Inside Back Cover.

Ion Beam Source and Power Supply: Ion Tech offers the $6 \times 66 \mathrm{~cm}$ RF Linear ion beam source for optical coatings and preclean applications. The source is designed for processes that move large substrates or large arrays of substrates across the narrow dimension of the rectangular crosssection beam either by linear translation or cylindrical rotation. The MPS-7000 ion beam power supply displays voltage and currents for beam, accelerator, decelerator, cathode, discharge, and neutralizer parameters. With the MPS-7000, users can store and recall up to 99 parameter sets.

Circle No. 63 on Inside Back Cover.

Force Measuring Instrument: The Molecular Force Probe ${ }^{\mathrm{TM}}$ from Asylum Research is a pico-Newton sensitive, singleaxis force measuring instrument that is five times more sensitive than commercially available atomic force microscopes. The technology is based around a flexible cantilever with a sharp tip that deflects in response to the small forces resulting from interactions between the cantilever tip and sample. A separate sensor linearizes the movement of the cantilever, and an open mechanical design allows for a range of samples and mounting schemes. Circle No. 70 on Inside Back Cover.

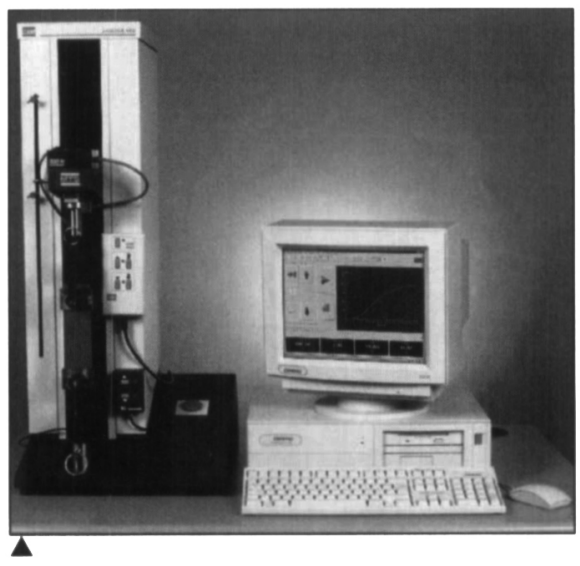

Material Testing Workstation: The Synergie $^{\mathrm{TM}} 1000$ from MTS Systems has a $5 \mathrm{kN}(1100 \mathrm{lbf})$ capacity and a compact design in which the electronic package is integrated into the load frame. The workstation is automated with TestWorks ${ }^{\circledR} 4$ material testing software, allowing users to analyze, review, graph, plot, and archive material testing data. The system is suitable for tensile, compression, flex, peel, shear, and standard test modes.

Circle No. 62 on Inside Back Cover.

Laser Diode Production Tool: The Discovery Laser Diode Machine ${ }^{\mathrm{TM}}$ from EMCORE is a fully configured InGaAsP, InGaAlP, and AlGaAs laser diode production tool that provides uniform thickness, doping, and composition. The system uses a $4 \times 6$-in. $(-10.2 \times 15.2-\mathrm{cm})$ wafer carrier configuration and includes subsystems to produce high-quality epitaxial material. The RealTemp ${ }^{\mathrm{TM}}$ wafer temperature measurement and control tool facilitates an accurate production process. Applications include telecommunications, surveying and positioning instruments, and as pump sources for other lasers.

Circle No. 64 on Inside Back Cover.

Low-Temperature Sensors and Instruments: Free catalog from Lake Shore features information on cryogenic temperature sensors, temperature controllers and monitors, current sources, temperature transmitters, and accessories. Included are sensor and instrument selection guides and sensor packaging information. A reference section compares strengths and weaknesses of available sensor types, outlines proper installation techniques for low-temperature instruments, and explains overail system performance. Circle No. 67 on Inside Back Cover.
Copper Plating Pulsed DC Power Supply: Advanced Energy Industries' EWave $^{\text {TM }}$ bipolar pulsed dc power supply is designed for the copper plating phase of dual-damascene process flow applications. The system has four independently controlled pulsed dc channels, and each channel stores 15 waveforms and 15 recipes. The host computer control allows waveforms to be changed instantly and four-terminal control and measurement of voltage at the wafer. The system is expandable to $300-\mathrm{mm}$ applications for higher current capability.

Circle No. 68 on Inside Back Cover.

Gamma Radiation Safety: The American Society for Nondestructive Testing offers a gamma radiation safety study guide to assist trainees in preparing for its Industrial Radiography Radiation Safety Personnel exam. The guide includes information on radiography history, radiation fundamentals, certification requirements, biological effects and control of radiation exposure, detection and measurement of radiation, gamma radiography equipment, and procedures for operation, emergencies, and transportation. Pertinent U.S. Nuclear Regulatory Commission information and forms, publications, and regional offices also are presented.

Circle No. 69 on Inside Back Cover.

UHV Windows: Bomco's ultrahigh vacuum windows permit the use of optical pyrometry, ellipsometry, light scattering, and reflectance-difference spectroscopy to obtain data in real time during MBE operations. The Re-Entrant UHV Window extends inside the vacuum chamber to save space. The flange is $4.5 \mathrm{in} .(\sim 11.4 \mathrm{~cm})$, the tube is 2.25 in. $(-5.7 \mathrm{~cm})$ outside diameter, and the depth of the unit is $4.5 \mathrm{in}$. $(\sim 11.4 \mathrm{~cm})$. The conventional UHV window, extending outside the vacuum chamber, is available in 1.5- and 2-in. ( $3.8-$ and $5.2-\mathrm{cm}$ ) flange sizes and can be protected by a stainless steel shield.

Circle No. 66 on Inside Back Cover.

Stainless Steel Ties: BAND-IT's cata$\log$ describes a line of stainless steel ties and application tools. The ties are available coated or uncoated in a range of lengths, widths, and thicknesses. Choice of features includes reusability and self-locking capabilities. A choice of stainless steel identification systems is also detailed. Applications include cable bundling and EMP/ EMI/RFI shield terminations.

Circle No. 65 on Inside Back Cover. 


\section{SCANCO MEDICAL}

\section{www.scanco.ch \\ X-Ray Microtomography Systems}
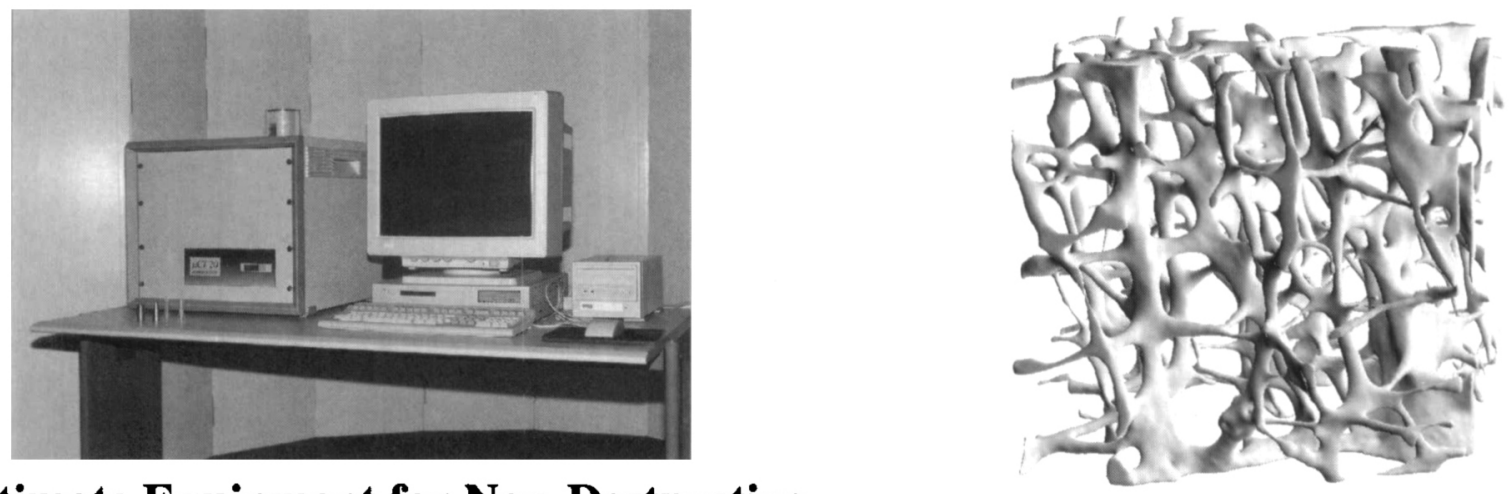

The Ultimate Equipment for Non-Destructive 3D Imaging and Analysis

Applications

- Orthopedics (Bone, Joints, Implants)

- Teeth

- Foams

- Ceramics

- Polymers

- Material Composites

- Biomineralization

- etc.

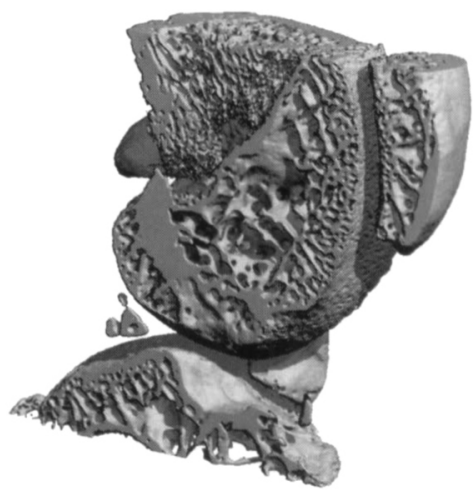

Features

- Desktop System

- Resolution up to $15 \mu \mathrm{m}$ (8 4 m voxel size)

- High Throughput (Batch Mode Processing)

- Max. Object Size up to $80 \mathrm{~mm}$

- No Routine Maintenance

- Variable Energy X-Ray Sources

- No Sample Preparation Required

- Sophisticated 3D-Evaluation

- Data Ready for Finite Element Analysis Programs

- Custom System Configuration available

For further information on these systems or contract scanning services please contact:

SCANCO Medical AG

Auenring 6-8, 8303 Bassersdorf, Switzerland tel +4118370710 fax +4118370713

SCANCO USA, Inc.

10 Lantern Lane, Wayne, PA 19087, USA

tel/fax 6102962056

info@scanco.ch www.scanco.ch
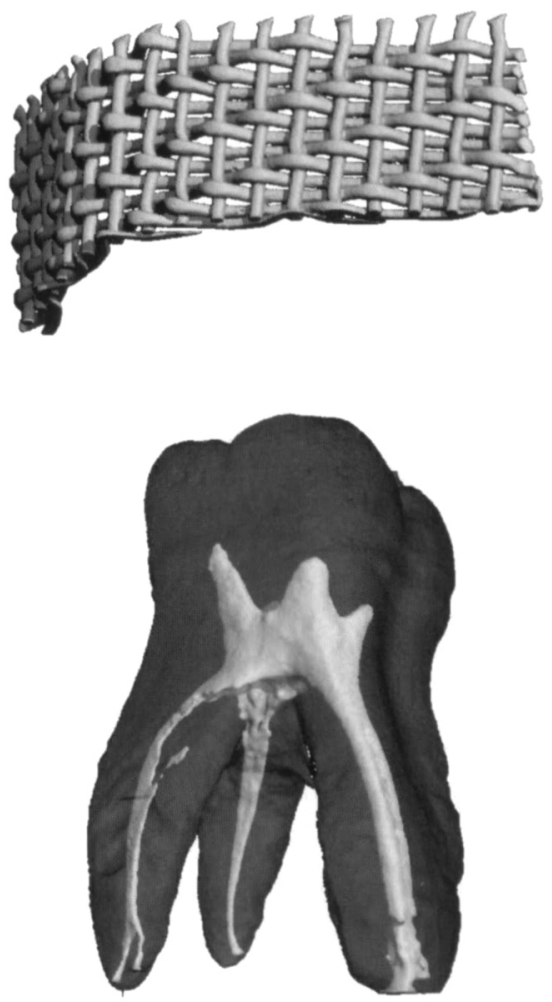